\title{
Polymer compositions for well killing operation in fractured reservoirs
}

\author{
S.R. Islamov \\ Postgraduate student, Saint Petersburg Mining University, St. Petersburg, Russia
}

A.V. Bondarenko

Student, Saint Petersburg Mining University, St. Petersburg, Russia

A.F. Gabibov

Student, Saint Petersburg Mining University, St. Petersburg, Russia

D.V. Mardashov

PhD, Associate professor, Saint Petersburg Mining University, St. Petersburg, Russia

\begin{abstract}
This article describes the results of physical, chemical and rheological properties of the frame and gel forming compositions, which are crosslinked systems prepared based on soluble silicates. The aim of this work is to increase the well killing efficiency during well service operations in the conditions of fractured carbonate reservoirs, high gas-oil ratio and abnormally low reservoir pressure. The technology of well killing during well service operation involves sequential injection into the well. The considered compositions showed that they could be used in conditions of reservoir temperatures from $20^{\circ} \mathrm{C}$ to $90^{\circ} \mathrm{C}$, which consists in the possibility of injection these compositions into a typical well and selling them into the bottom-hole formation zone due to their low viscosity after preparation and slow cross-linking speed. Laboratory tests showed the high efficiency of the use of blocking polymer compositions, and opened new directions for further research, namely, the need for a cycle of laboratory and field tests of the considered compositions, which will allow us to choose and justify the optimal technological and economic parameters of the operation. The results can be applied to increase the well killing efficiency of oil and gas wells in complicated conditions during well service operations.
\end{abstract}

\section{INTRODUCTION}

Currently, based on the assessment of reserves, the share of carbonate reservoirs accounts for about $60 \%$ of hydrocarbon fields and about the same amount of oil production in the world. The development of such reservoirs is complicated by the presence of an extensive network of natural and artificial (as a result of hydraulic fracturing) fractures, high heterogeneity, complex structure of the pore space, hydrophobic properties of reservoir rocks and abnormally low reservoir pressure.

The considered characteristic features of carbonate reservoirs can lead to low coverage of the formation impact, low displacement efficiency, quick well flooding, gas breakthrough, and, as a result, a rapid decline in oil production (Bouts et al. 1997; Dorman \& Udvary 1996; Rogachev \& Strizhnev 2006).

The presence of reservoirs with similar characteristics in the field requires a special, differentiated approach to planning well killing operations related to the development and selection of blocking composition. The correct selection of blocking compositions for well killing requires careful laboratory tests for specific objects of the planned application. 
Failure to comply with the above conditions when planning activities at the well may lead to the loss of significant volumes of process fluids, increase the repair and response time, which, ultimately, will lead to an increase in the cost of well service operations (Dandekar 2013; Jouenne et al. 2006).

An advanced solution in the development of blocking fluids is the use of cross-linked polymer compositions with time-controlled gelation. The rate of change of viscosity can be adjusted to more efficiently carry out technological operations.

Technologies using the described polymer compositions have proven to be a reliable method for isolating highly permeable reservoir intervals in order to prevent water and gas breakthrough into production wells (Gumerova \& Yarkeyeva 2017).

As part of this work, the physical, chemical and rheological properties of the frame and gel forming compositions were selected and studied as blocking polymer fluids for well killing.

These compositions are crosslinked systems based on soluble silicates. In this case, a silicate gel is formed when an aqueous solution with a relatively high $\mathrm{pH}$, containing a sufficient amount of orthosilicic acid ester monomer or orthosilicic acid oligomers, experiences a decrease in its $\mathrm{pH}$, or is exposed to hardness cations (Volkov et al. 2019; Musabirov et al. 2019; Tokunov \& Saushin 2004).

The technology for well killing during well service operation involves sequential injection of frame and gel forming compositions into the well.

The procedure for conducting laboratory physical, chemical and rheological tests of compositions consisted of several consecutive stages:

1) determination of density;

2) assessment of thermal stability;

3) assessment of destruction;

4) determination of effective viscosity and static shear stress;

5) determination of the gelation time of cross-linked compositions.

\section{MATERIALS AND METHODS}

\subsection{Investigation of physical and chemical properties of compositions}

The frame-forming composition is an opaque non-uniform white liquid. When injected into the reservoir, the liquid phase is separated, and the dry residue is "baked" at elevated temperatures, forming a strong frame-forming screen for isolating intervals with increased fracturing. This feature of the composition allows to reduce the fluid loss into the well during well killing operation.

In turn, the gel-forming compositions are a transparent homogeneous liquid, which due to its high viscosity has a low filtration index in the reservoir, and is also able to prevent gas breakthrough in high gas-oil ratio conditions. At the same time, the gel-forming composition was prepared in two versions with a gel-forming agent for low $\left(20^{\circ} \mathrm{C}\right)$ and high $\left(90^{\circ} \mathrm{C}\right)$ temperatures.

The density of the frame and gel forming compositions was determined by the pycnometric method according to (GOST 3900-85 2006) and amounted to $1045 \mathrm{~kg} / \mathrm{m}^{3}$ and $1015 \mathrm{~kg} / \mathrm{m}^{3}$ for low temperatures, and for high temperatures $-1022 \mathrm{~kg} / \mathrm{m}^{3}$ ), respectively. This value of the density of the studied compositions allows them to be used at normal and reduced values of reservoir pressure (Galimkhanov et al. 2019; Rogachev \& Kondrashev 2016).

To assess the thermal stability, the prepared composition fulfilled in a thermostat at a temperature of $20^{\circ} \mathrm{C}$ or $90^{\circ} \mathrm{C}$ for 3 days (average duration of well service operation). Then the state of the composition under study and the change in its appearance were visually evaluated. The composition was considered unstable when the water phase was isolated, stratified, and precipitated.

The destructibility of the frame and gel forming compositions was evaluated visually at temperatures of $20^{\circ} \mathrm{C}$ and $90^{\circ} \mathrm{C}$ for 24 hours by mixing the destructor with the studied blocking compositions in 1:1 ratios. A $10 \%$ aqueous solution of sodium hydroxide was used as the 
destructor of the gel-forming composition, and a mixture of $12 \%$ hydrochloric and $5 \%$ hydrofluoric acids was used for the destruction of the frame-forming composition.

\subsection{Determination of the rheological properties of the compositions}

The study of rheological properties of the frame and gel forming compositions consisted in determining the following parameters:

- effective viscosity at $300 \mathrm{rpm}$;

- "viscosity curves" (dependence of the effective viscosity on the shear rate or rotor speed);

- Static shear stress after gelation of cross-linked compositions in the controlled shear rate mode by plotting the dependence of the shear stress $\tau$ on the shear rate $\mathrm{D}$, determining the shear stress at which the structure of the composition begins to collapse and move;

- time of gelation of cross-linked compositions in the "dynamic" mode by measuring the effective viscosity $\mu_{\text {eff }}$ of the composition in time at a given shear rate equal to the rate of injection of the composition into the well, and in the "static" mode of oscillating stresses by measuring the complex viscosity in time.

The construction of the "viscosity curve" and the determination of the static shear stress was carried out for the frame and gel forming compositions. Static shear stress characterizes the initial pressure gradient at which the structure of the composition collapses and moves (Strizhnev 2010).

Experiments to determine the gelation time were performed only for cross-linked compositions that are nonlinear gels.

Determination of rheological characteristics is carried out according to (GOST 1929-87 2002) with the use of automated rotary viscometer Rheotest RN 4.1 (Figure 1). Measurements were made using a cylindrical measuring system.

I. Sequence of studies of linear (non-crosslinked) compositions:

1. Modeling the process of starting the movement of the composition (destruction of the structure of the composition). The static shear stress is determined by plotting the dependence of the shear stress on the shear rate in the controlled shear stress mode. The static shear stress is equal to the value of the shear stress $\tau$, preceding the destruction of the structure of the composition, and characterizes the beginning of the movement of the composition. The conditions of the experiment:

- pre-exposure of the composition in the measuring cell for 15 minutes;

- experiment time $\mathrm{t}=0-500 \mathrm{~s}$;

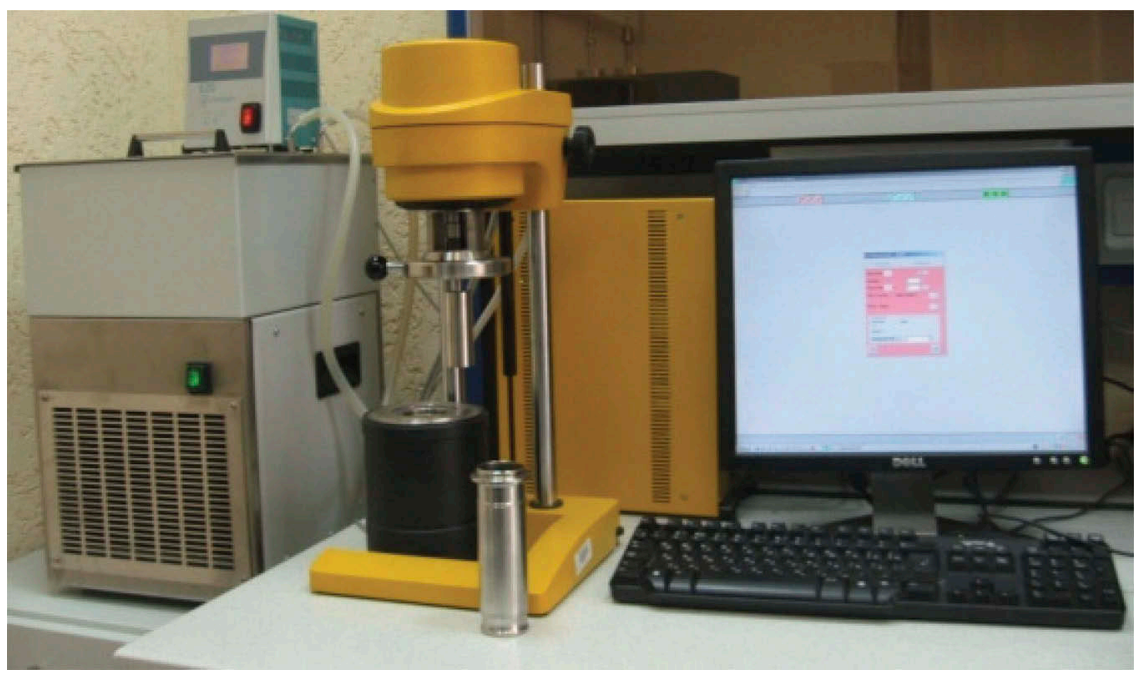

Figure 1. Rotational automated viscometer Rheotest RN 4.1. 
- shear stress $\tau=0-2000 \mathrm{~Pa}$;

- temperature $\mathrm{T}=20-90^{\circ} \mathrm{C}$, respectively.

2. Determination of the effective viscosity was carried out in the controlled shear rate "viscosity curve" (CR test - Controlled Rate). The essence of the research method was to obtain the dependence of the effective viscosity (shear stress) on the shear rate (rotational speed) with a gradual increase in the last parameter from 0 to $300 \mathrm{~s}^{-1}$. The conditions of the experiment:

- experiment time $\mathrm{t}=0-300 \mathrm{~s}$;

- shear rate $\gamma=0-300 \mathrm{~s}^{-1}$;

- temperature $\mathrm{T}=20-90^{\circ} \mathrm{C}$, respectively.

II. Due to the fact that the gel-forming composition changes the viscosity over time, it was decided to conduct a step-by-step study of rheological characteristics according to the following scheme (Raupov \& Oprikova 2018; Ryabokon 2009):

1. Modeling the state of the composition immediately after preparation at the wellhead to assess filterability in the inter-tube space or in a column of tubing. The effective viscosity of the composition at different shear rates is determined by removing the "viscosity curve". The conditions of the experiment:

- experiment time $\mathrm{t}=0-300 \mathrm{~s}$;

- shear rate $\gamma=0-300 \mathrm{~s}^{-1}$;

- temperature $\mathrm{T}=20^{\circ} \mathrm{C}$.

2. Modeling the process of pumping the composition through the tube space into the well, taking into account the uniform temperature change along the well bore. The gelation time is determined at a constant shear rate. The conditions of the experiment:

- experiment time $\mathrm{t}=85 \mathrm{~min}$;

- shear rate $\gamma=21.8 \mathrm{~s}^{-1}$;

- temperature $\mathrm{T}=20-90^{\circ} \mathrm{C}$ (for the composition applicable at $20^{\circ} \mathrm{C}$, the experiment temperature $\mathrm{T}=20^{\circ} \mathrm{C}$ ).

3. Modeling the process of pumping the composition into the space of the production string. The determination of the gelation time at a constant shear rate continues. The conditions of the experiment:

- experiment time $\mathrm{t}=15$ min;

- shear rate $\gamma=7.1 \mathrm{~s}^{-1}$;

- temperature $\mathrm{T}=90^{\circ} \mathrm{C}$ (for a composition applicable at $20^{\circ} \mathrm{C}$, the experiment temperature $\mathrm{T}=20^{\circ} \mathrm{C}$ ).

4. Modeling the process of holding the composition for the reaction time (the end of the crosslinking process) at the reservoir temperature. The time of gelation in the static mode of oscillating stresses is determined (Elchin et al. 2019; Quintero et al. 2017). The conditions of the experiment:

- experiment time $\mathrm{t}=3 \mathrm{~h}$;

- the oscillation frequency of the rotor $\mathrm{f}=1 \mathrm{~Hz}$;

- voltage modulus $\mathrm{G}=10 \mathrm{~Pa}$;

- temperature $\mathrm{T}=90^{\circ} \mathrm{C}$ (for a composition applicable at $20^{\circ} \mathrm{C}$, the experiment temperature $\mathrm{T}=20^{\circ} \mathrm{C}$ ).

5. Modeling the process of starting the movement of the composition (destruction of the structure of the composition). The static shear stress is determined by plotting the dependence of the shear stress on the shear rate in the controlled shear stress mode. The conditions of the experiment:

- experiment time $\mathrm{t}=0-500 \mathrm{~s}$;

- shear stress $\tau=0-2000 \mathrm{~Pa}$;

- temperature $\mathrm{T}=90^{\circ} \mathrm{C}$ (for the composition used at $20^{\circ} \mathrm{C}$, the experiment temperature $\mathrm{T}=20^{\circ} \mathrm{C}$ ).

6. Modeling the state of the composition after injection into the well to assess changes in its effective viscosity. The effective viscosity of the composition at different shear rates is determined by removing the "viscosity curve". The conditions of the experiment: 
- experiment time $\mathrm{t}=0-300 \mathrm{~s}$;

- shear rate $\gamma=0-300 \mathrm{~s}^{-1}$;

- temperature $\mathrm{T}=90^{\circ} \mathrm{C}$ (for the composition used at $20^{\circ} \mathrm{C}$, the experiment temperature $\left.\mathrm{T}=20^{\circ} \mathrm{C}\right)$.

\section{RESULTS AND DISCUSSION}

The evaluation of thermal stability of frame-forming composition (Table 1) revealed that 15 min after preparation of the composition at $20^{\circ} \mathrm{C}$ and $90^{\circ} \mathrm{C}$ of the composition is given up to 20 and $25 \%$ of water, respectively. When further thermostating, the amount of water released remains virtually unchanged. At the same time, the producer of the frame-forming composition allows the release of water in a small amount from the volume of the composition. Therefore, it was decided that the frame-forming composition is thermal stable at $20^{\circ} \mathrm{C}$ and $90^{\circ} \mathrm{C}$ and is able to maintain its physical and chemical properties during well service and workover operations.

At the same time, when the gel-forming composition was thermostated, no visible changes in appearance were observed during the entire period time.

It is worth noting that the requirement for such a type of composition in well killing operation is their complete or partial destructibility when exposed to a destructor. Compositions that do not meet these conditions cannot be recommended for use. Since this entails a deterioration of the reservoir's filtration and reservoir properties, as well as difficulties in developing and bringing the well back to normal after well service and workover operations.

The destructibility of the frame and gel forming compositions was evaluated visually at temperatures $20-90^{\circ} \mathrm{C}$ for 24 hours by mixing the destructor with the studied blocking compositions in 1:1 ratios. A 10\% aqueous solution of sodium hydroxide was used as the destructor of the gel-forming composition, and a mixture of $12 \%$ hydrochloric and $5 \%$ hydrofluoric acids was used for the destruction of the frame-forming composition.

As a result of evaluating the destruction of the frame and gel forming compositions (Table 2) it was found that these compositions can be recommended for use in the well-killing process. The results of evaluating the destruction of the frame and gel compositions showed the following:

- the gel-forming composition is completely destroyed within 1 and 3 hours with a $10 \%$ aqueous $\mathrm{NaOH}$ solution at 90 and $20^{\circ} \mathrm{C}$, respectively;

- the frame-forming composition is destroyed by $75 \%$ within 24 hours with a mixture of $12 \%$ hydrochloric and $5 \%$ hydrofluoric acids (mud acid) at 90 and $20^{\circ} \mathrm{C}$, respectively. The future observation showed insignificant changes because when reacting with a frame-forming composition, mud acid loses reactivity.

Summarized results of rheological tests of the compositions are presented in Table 3.

The results of determining the gelation time under the conditions of injection of crosslinked compounds are shown in Figures 2-3.

Based on the results presented in (William et al. 1996), the higher the static shear stress, the greater the pressure gradient blocking composition is able to withstand without collapsing. The same conclusions are valid when the effective viscosity increases, since it increases its structural strength.

Table 1. Results of determining the thermal stability of the frame and gel forming compositions.

\begin{tabular}{|c|c|c|c|c|}
\hline No. & $\begin{array}{l}\text { Composition } \\
\text { name }\end{array}$ & $\begin{array}{l}\text { Thermal stability at } \\
20^{\circ} \mathrm{C} \text { for } 3 \text { days }\end{array}$ & $\begin{array}{l}\text { Thermal stability at } \\
90^{\circ} \mathrm{C} \text { for } 3 \text { days }\end{array}$ & Remark \\
\hline 1 & Frame-forming & + & + & \multirow{2}{*}{$\begin{array}{l}\text { Allocation of up to } 20 \text { and } 25 \% \\
\text { of water, respectively } \\
\text { - }\end{array}$} \\
\hline 2 & Gel-forming & + & + & \\
\hline
\end{tabular}


Table 2. Results of evaluation of the destruction processes of the frame and gel forming compositions.

\begin{tabular}{lllllll}
\hline No. & $\begin{array}{l}\text { Composition } \\
\text { name }\end{array}$ & $\begin{array}{l}\text { Temperature, } \\
{ }^{\circ} \mathrm{C}\end{array}$ & $\begin{array}{l}\text { Destruction } \\
\text { results }\end{array}$ & $\begin{array}{l}\text { Destruction } \\
\text { time, } \mathrm{h}\end{array}$ & Destructor & $\begin{array}{l}\text { Recommendation } \\
\text { for use }\end{array}$ \\
\hline 1 & $\begin{array}{l}\text { Frame- } \\
\text { forming }\end{array}$ & 20 & Partially & $\begin{array}{l}1(50 \%) \\
24(75 \%)\end{array}$ & $12 \% \mathrm{HCl}+5 \% \mathrm{HF}$ & Recommended \\
2 & $\begin{array}{l}\text { Frame- } \\
\text { forming }\end{array}$ & 90 & Partially & $\begin{array}{l}1(50 \%) \\
24(75 \%)\end{array}$ & $12 \% \mathrm{HCl}+5 \% \mathrm{HF}$ & Recommended \\
3 & $\begin{array}{l}\text { Gel-forming } \\
4\end{array}$ & 20 & Completely & $3(100 \%)$ & $\begin{array}{l}10 \% \text { aqueous } \\
\mathrm{NaOH} \text { solution }\end{array}$ & Recommended \\
& Gel-forming & 90 & Completely & $1(100 \%)$ & $\begin{array}{l}10 \% \text { aqueous } \\
\mathrm{NaOH} \text { solution }\end{array}$ & Recommended \\
\hline
\end{tabular}

Table 3. Results of rheological studies of the frame and gel forming compositions.

\begin{tabular}{lllll}
\hline & $\begin{array}{l}\text { Effective viscosity (mPa's) } \\
\text { after preparation at }\end{array}$ & $\begin{array}{l}\text { Effective viscosity (mPa's) } \\
\text { after crosslinking at } \\
\mathrm{N}=300 \mathrm{rpm}\end{array}$ & $\begin{array}{l}\text { Static } \\
\text { shear } \\
\text { stress, Pa }\end{array}$ \\
\hline 1 & Frame-forming at $20^{\circ} \mathrm{C}$ & 27 & - & 2.66 \\
2 & Frame-forming at $90^{\circ} \mathrm{C}$ & 64 & - & 3.38 \\
3 & Gel-forming at $20^{\circ} \mathrm{C}$ & 10.7 & 17.4 & 126 \\
4 & Gel-forming at $90^{\circ} \mathrm{C}$ & 8 & 600 & 648 \\
\hline
\end{tabular}

Notes:

"-"means that the effective viscosity for these compositions was not measured, since these compositins are not "cross-linked" and their viscosity does not depend on time

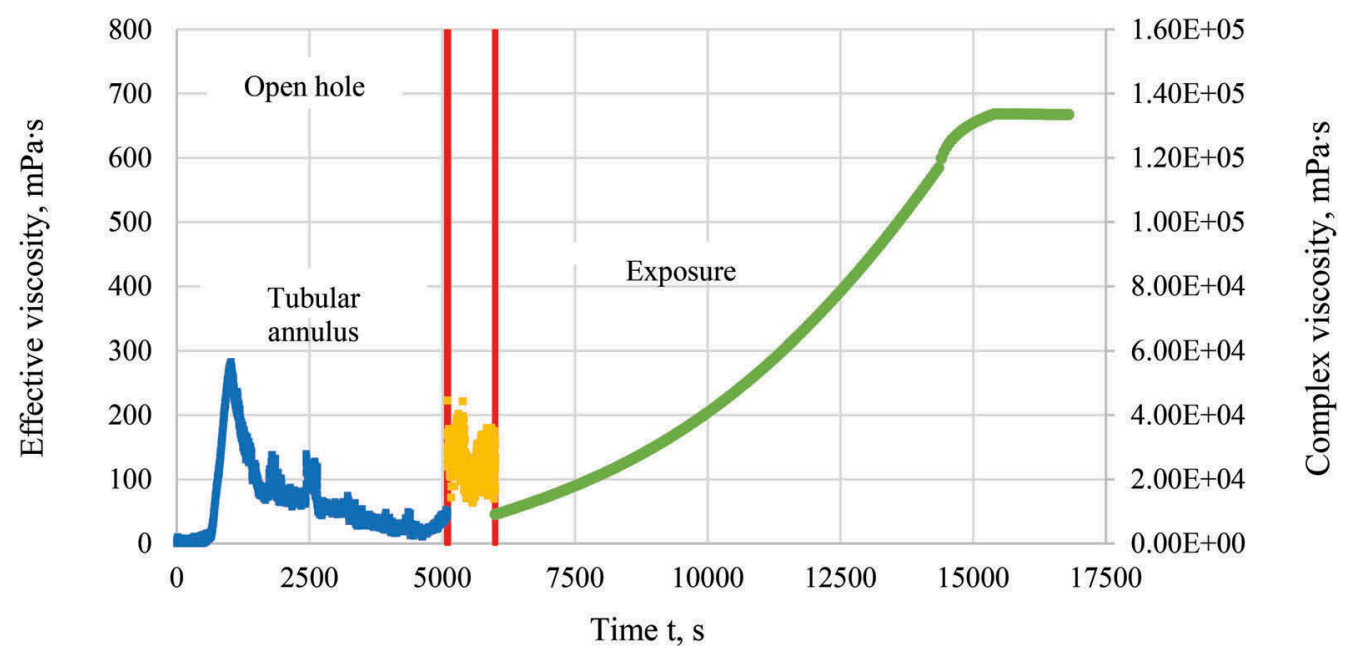

Figure 2. Dynamics of effective and complex viscosity of the gel-forming composition $\left(90^{\circ} \mathrm{C}\right)$.

Based on the results of determining the crosslinking time in the process of modeling the injection of a gel-forming composition (used for $20^{\circ} \mathrm{C}$ ) into a conditional well, it was found that: 


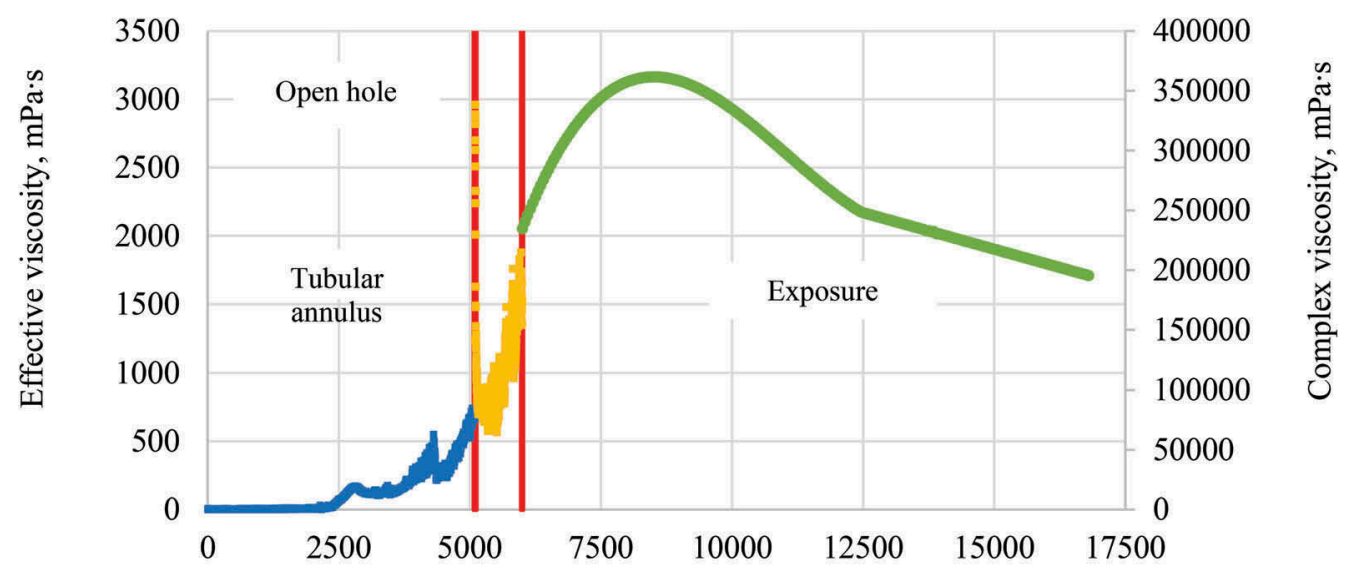

Time $t, s$

Figure 3. Dynamics of effective and complex viscosity of the gel-forming composition $\left(20^{\circ} \mathrm{C}\right)$.

- the crosslinking process begins during the injection of the compound into the inter-tube space. The induction period of the beginning of gelation is about 40 minutes after the preparation of the composition.

- the process of crosslinking the composition ends after its injection into the well, during the technical settling of the well. The induction period of the end of gelation is about $2 \mathrm{~h} 20$ min after preparation of the composition.

Based on the results of determining the crosslinking time in the process of modeling the injection of a gel-forming composition (used for $90^{\circ} \mathrm{C}$ ) into a conditional well, it was found that:

- the crosslinking process begins during the injection of the compound into the inter-tube space. The induction period of the beginning of gelation is about 12 minutes after the preparation of the composition.

- the process of crosslinking the composition ends during its injection into the inter-tube space.

The induction period of the end of gelation is about 18 minutes after the preparation of the composition. After injection of the composition into the well, during the technical settling of the well, structure formation is observed, characterized by an increase in the complex viscosity, which ends after 4 hours from the moment of preparation of the composition. In order to increase the technological efficiency (for example, to prevent mechanical destruction of the gel during its injection into the well) of the silencing process using the gel-forming composition used for $90^{\circ} \mathrm{C}$, it is recommended to adjust the content of the components so that the gelforming process ends after the composition is fully injected into the well.

\section{CONCLUSION}

Based on the laboratory tests of physical, chemical and rheological properties of the frame and gel forming compositions, the following findings have been established:

1. Compositions in the conditions of low $\left(20^{\circ} \mathrm{C}\right)$ and high $\left(90^{\circ} \mathrm{C}\right)$ temperatures are thermostable during the entire researched period ( 3 days).

2. The results of evaluating the destruction of the frame and gel compositions showed the following: 
- the gel-forming composition is completely destroyed within 1 and 3 hours with a $10 \%$ aqueous $\mathrm{NaOH}$ solution at 90 and $20^{\circ} \mathrm{C}$, respectively;

- the frame-forming composition is destroyed by $75 \%$ within 24 hours with a mixture of $12 \%$ hydrochloric and 5\% hydrofluoric acids (mud acid) at 90 and $20^{\circ} \mathrm{C}$, respectively. The future observation showed insignificant changes because when reacting with a frame-forming composition, mud acid loses reactivity.

3. The gel (8 and $10.7 \mathrm{mPa} \cdot \mathrm{s})$ and frame (64 and $27 \mathrm{mPa} \cdot \mathrm{s})$ forming compositions at 20 and $90^{\circ} \mathrm{C}$, respectively, have a low effective viscosity after preparation, which allows us to conclude that they are technologically efficient when injected into the well;

4. Gel-forming composition can have a high blocking capacity, since their static shear stress is $648 \mathrm{~Pa}$ at low temperatures $\left(20^{\circ} \mathrm{C}\right)$ and $126 \mathrm{~Pa}$ at high temperatures $\left(90^{\circ} \mathrm{C}\right)$.

The results of physical, chemical and rheological studies of frame and gel forming compositions have shown that they can be used in conditions of reservoir temperatures from $20^{\circ} \mathrm{C}$ to $90^{\circ} \mathrm{C}$, which consists in the possibility of injection these compositions into a typical well and selling them into the bottom-hole formation zone due to their low viscosity after preparation and slow cross-linking speed. However, based on the results of the conducted studies, it is recommended to adjust the content of the components of the gel-forming composition (used for $90^{\circ} \mathrm{C}$ ) so that the gel-forming process ends after the composition is injected into the well in full.

In addition, the use of destruction allows to reduce the negative impact of this technology on filtration characteristics of the bottomhole formation zone after well killing due to the reduction of the coefficient of relative changes in permeability and pressure gradient the start of oil flow when "development" wells.

To address the problem of well killing in complicated conditions, it is necessary to conduct a cycle of laboratory and field tests of the considered compositions, which will allow to select and justify the optimal technological and economic parameters of the operation.

\section{REFERENCES}

Bouts, M.N., Ruud, A.T. \& Samuel, A.J. 1997. Time Delayed and Low-Impairment Fluid-loss Control Using a Succinoglycan Biopolymer with an Internal Acid Breaker. SPE Journal, doi: 10.2118/31085PA, 21-23 December. Texas: Houston.

Dandekar, A.Y. 2013. Petroleum Reservoir Rock and Fluid Properties. Boca Raton: CRC press.

Dorman, J. \& Udvary, F. 1996. Comparative Evaluation of Temporary Blocking Fluid Systems for Controlling Fluid Loss Through Perforations. SPE Formation Damage Control Symposium, doi: 10.2118/ 31081-MS, 14-15 February. Louisiana: Lafayette.

Elchin, F.V., Azizagha, A.A., Vugar, V.G. \& Nurana, V.N. 2019. Water Shutoff Using Crosslinked Polymer Gels. SPE Annual Caspian Technical Conference, doi: 10.2118/198351-MS, 16-18 October. Azerbaijan: Baku.

Galimkhanov, A., Okhotnikov, D., Ginzburg, L., Bakhtin, A., Sidorov, Y., Kuzmin, P., Kulikov, S., Veliyev, G. \& Badrawi, M. 2019. Successful Implementation of Managed Pressure Drilling Technology Under the Conditions of Catastrophic Mud Losses in the Kuyumbinskoe Field. SPE Russian Petroleum Technology Conference, doi: 10.2118/196791-MS, 22-24 October. Russia: Moscow.

GOST 3900-85. 2006. Oil and Oil products. Density Determination Methods. Moscow: Publishing Standards.

GOST 1929-87. 2002. Oil Products. Methods for Determination of Dynamic Viscosity on a Rotational Viscometer. Moscow: Publishing Standards.

Gumerova, G.R. \& Yarkeyeva, N.R. 2017. Technology of using cross-linked polymer compositions. Journal of Oil \& Gas Business, 2, 63-79.

Jouenne, S., Klimenko, A. \& Levitt, D. 2016. Tradeoffs Between Emulsion and Powder Polymers for EOR. SPE Improved Oil Recovery Conference, doi: 10.2118/179631-MS, 11-13 April. Oklahoma: Tulsa.

Musabirov, M.Kh., Kuryashov, D.A., Garifov, K.M., Dmitriyeva, A.Y. \& Abusalimov E.M. 2019. Developing structure-forming colloidal systems for matrix acidizing of porous-fractured carbonate reservoirs. Oil Industry Journal, 6, 71-73. 
Quintero, L., Ponnapati, R. \& Felipe, M. 2017. Cleanup of Organic and Inorganic Wellbore Deposits Using Microemulsion Formulations: Laboratory Development and Field Applications. Offshore Technology Conference, doi: 10.4043/27653-MS, 1-4 May. Texas: Houston.

Raupov, I.R. \& Oprikova, V.Y. 2018. The results of laboratory studies of the rheological characteristics of the crosslinked polymer composition. Bulatovskie chteniya, 2, 63-66.

Rogachev, M.K. \& Strizhnev, K.V. 2006. Complication Control During Oil Production. Moscow: Nedra Business Center.

Rogachev, M.K. \& Kondrashev, A.O. 2016. Substantiation of the technology of in-situ waterproofing in low-permeability reservoirs. Journal of Mining Institute, 217, 55-60.

Ryabokon, S.A. 2009. Technological Fluids for Completion and Well Service Operations. Krasnodar: Prosveshcheniye-Yug.

Strizhnev, K.V. 2010. Repair and Insulation Works in Wells: Theory and Practice. St. Petersburg: Nedra.

Tokunov, V.I. \& Saushin, A.Z. 2004. Process Fluids and Compositions for Increasing the Productivity of Oil and Gas Wells. Moscow: Nedra.

Volkov, V., Turapin, A., Ermilov, A., Vasyutkin, S., Fomin, D. \& Sorokina, A. 2019. Experience of Gas Wells Development in Complex Carbonate Reservoirs in Different Stages of Development. SPE Russian Petroleum Technology Conference, doi:10.2118/196915-MS, 22-24 October. Russia: Moscow.

William, E., Syed, A. \& Mingjie, K. 1996. Effects of Completion Fluid Loss on Well Productivity. SPE Formation Damage Control Symposium, doi: 10.2118/31137-MS, 14-15 February. Louisiana: Lafayette. 